\title{
BRAGANTIA
}

Revista Científica do Instituto Agronômico, Campinas

Vol. 41

Campinas, junho de 1982

Nota.$^{o} 6$

\section{AMOSTRAGEM DE FOLHAS DE MILHO PARA FINS DE DIAGNOSE DE NUTRIÇÃO NITROGENADA (1)}

Arquimenes Lavorenti, Seção de Química Analítica, Paulo Boller Gallo, Estação Experimental de Mococa, Eduardo SAwazakx (2), Seçāo de Milho e Cereais Diversos, e RÚtTER HIROCE, Seção de Química Analítica, Instituto Agronômico.

E bastante conhecida a importância do nitrogênio para o milho, cuja carência pode ser detectada através de sintomas manifestados pelas folhas e relacionados com baixos teores do nutriente. Embora sua aplicação tardia não tenha aumentado a produção do milho (6), o diagnóstico de sua carência permite tomada de medidas preventivas para o próximo cultivo na área carente. $A$ análise química foliar constitui uma técnica que permite conhecer o estado nutricional da planta de áreas com fertilidade desconhecida e, desse modo, estimar a necessidade de fertilização e conhecer também efeitos de outros fatores que afetam a nutrição de plantas em condições de campo (5).
0 estádio de desenvolvimento mais utilizado para a diagnose foliar do milho é o do florescimento, que corresponde a onze semanas após o plantio (2), por constituir uma fase de grande demanda de nutrientes na maioria das variedades (7). Enquanto nos Estados Unidos da América do Norte, coleta-se, na época do florescimento, a folha abaixo e oposta à primeira espiga para o estudo da diagnose foliar do milho (10), no Brasil, a partir de 1963 (4), coleta-se, na idade de nove semanas, o terço basal da folha de posição +4 , ou seja, a quarta folha a partir do ápice, considerando a primeira aquela de posição mais alta em que a

(1) Recebido para publicação a 22 de janeiro de 1981.

(2) Com bolsa de suplementacão do $\mathrm{CNPq}$. 
interseção da lâmina com a bainha é visível.

\section{ANDRADE (1) comparou} efeitos de variedades nos teores de nutrientes da folha +4 aos 60 dias e da folha abaixo e oposta à espiga, no florescimento.

O presente trabalho visou comparar, numa mesma idade, a sensibilidade da folha +4 , da folha da espiga e da abaixo e oposta à espiga no estudo da nutrição nitrogenada do milho.

Material e métodos: 0 experimento foi instalado no ano agrícola 1979/80 na Estação Experimental de Mococa, Instituto Agronômico, Campinas (SP). O solo pertence ao Grande Grupo Podzólico Vermelho-Amarelo orto. Aplicaram-se $2.500 \mathrm{~kg} / \mathrm{ha}$ de calcário dolomítico para correção de acidez e uma adubação básica de $300 \mathrm{~kg} /$ /ha da fórmula 4-14-8 de NPK para elevar o nível de fertilidade. As análises químicas do solo antes do plantio do milho apresentaram os seguintes resultados: $\mathrm{pH}=$ 5,9 ; matéria orgânica $=2,0 \%$; $\mathrm{Al}=$ traços $; \mathrm{Ca}^{2+}=2,4 \mathrm{e}^{\mathrm{Mg}}{ }^{2+}$ $=1,1 \mathrm{meq} / 100 \mathrm{ml}$ de solo: $\mathrm{P}=$ $4 \mathrm{e} \mathrm{K}=152, \mathrm{em} \mu \mathrm{g} / \mathrm{ml}$ do solo. Os teores de $\mathbf{P}$ são considerados médios e os de $\mathrm{K}$, elevados.

$O$ experimento foi delineado em blocos ao acaso com três tratamentos e cinco repetições. Os tratamentos consistiram na aplicação em cobertura de 0,30 e $60 \mathrm{~kg} / \mathrm{ha}$ de $\mathrm{N}$, na forma de sulfato de amônio, aos 35 dias após a emergência do milho. Em todos os tratamentos, foram aplicados no sulco do plantio, durante a semeadura, $12 \mathrm{~kg} / \mathrm{ha}$ de $\mathrm{N}$, através da fórmula 4-14-8.

Cada parcela constou de seis linhas de 5m, espaçadas de $1 \mathrm{~m}$. Vinte dias após a germinação, realizou-se o desbaste, deixando-se cinco plantas por metro linear. Para o cômputo da produção, foram consideradas as duas linhas centrais, excluindo-se $0,50 \mathrm{~m}$ de cada extremidade. A semeadura foi efetuada a 15 de outubro de 1979 com o milho híbrido 'IAC Hmd 7974'. As amostragens de folhas foram efetuadas numa mesma época, aos 67 dias após a germinação, coincidindo com a época do florescimento. Foram coletadas folhas de três posiçôes da mesma planta: a) folha +4 ; b) folha da espiga; c) folha abaixo e oposta à primeira espiga, num total de vinte folhas de cada posição por parcela experimental.

Foram cortados com tesoura cerca de $20 \mathrm{~cm}$ de comprimento do terço basal das folhas, deixando-se cerca de $5 \mathrm{~cm}$ junto à inserção da folha no colmo. Dessa parte basal foram aproveitadas as lâminas clorofiladas para análises 
químicas, sendo desprezada a nervura central. O preparo das amostras e as determinaçōes dos teores de $\mathrm{N}, \mathrm{P}, \mathrm{K}, \mathrm{Ca}, \mathrm{Mg}$ e $\mathrm{S}$ foram efetuados segundo técnicas descritas por BATAGLIA et alïi (3). Por ocasião da colheita, foram coletadas amostras de grãos de cada parcela, nas quais foram determinados os mesmos nutrientes analisados nas folhas.

Resultados e discussão: A avaliação da folha mais adequada ao estudo da nutrição mineral de planta é feita pela análise da variância dos teores de nutrientes contidos nas folhas de plantas submetidas às diferentes doses de fertilizantes, pelo coeficiente de correlação entre os teores dos nutrientes das folhas a a produção e pelo coeficiente de variação do experimento. A análise da variância dos teores de nutrientes mostra o efeito diferencial das doses de nutrientes; o coeficiente de correlação entre os teores de nutrientes e a produção mostra o efeito simultâneo dos nutrientes nesses parâmetros, e o coeficiente de variação revela a homogeneidade dos teores dos nutrientes.

Pelo quadro 1 nota-se que a folha +4 apresentou, na análise da variância, valor de $\mathrm{F}$ significativo e mais elevado do que nas outras folhas, o coeficiente de correlação entre $\mathrm{N}$ das folhas e a produção mais elevado, embora não significativamente (9) e o coeficiente de variação menor, revelando, na época da amostragem, ser a folha fisiologicamente recém-madura e, portanto, contendo teores de nitrogênio nas folhas menos heterogêneos de plantas de uma parcela para outra. A folha que revela maior sensibilidade aos efeitos da adubação e que apresenta menor variação do teor de nutrientes é a que melhor se presta ao estudo da nutriçāo mineral de plantas, embora, em casos de carência aguda de um nutriente qualquer folha ou mesmo qualquer órgão sirva ao objetivo proposto.

Nota-se, pelo quadro 2, que o adubo nitrogenado, além do efeito sobre os teores de $\mathrm{N}$, teve efeito positivo nos teores de $\mathrm{P}, \mathrm{S}$ e $\mathrm{Ca}$ das folhas +4 , nos teores de $P$ e $S$ da folha da espiga e nos de $K$ da folha abaixo e oposta à espiga. $O$ efeito no teor de $\mathrm{S}$ das folhas é explicado pelo teor de $S$ no sulfato de amônio e no de $\mathrm{P}$ e $\mathrm{Ca}$, por haver sinergismo com o $\mathrm{N}$ (8). Nos grãos, o efeito do adubo nitrogenado foi pouco acentuado e os teores dos macronutrientes foram mais baixos do que os das folhas, exceto o fósforo.

Conclusão: Desses resultados, conclui-se que, na época da emissão de inflorescência do milho, a folha de posição +4 foi a que apresentou melhor sensibilidade para o estudo da nutrição nitrogenada. 


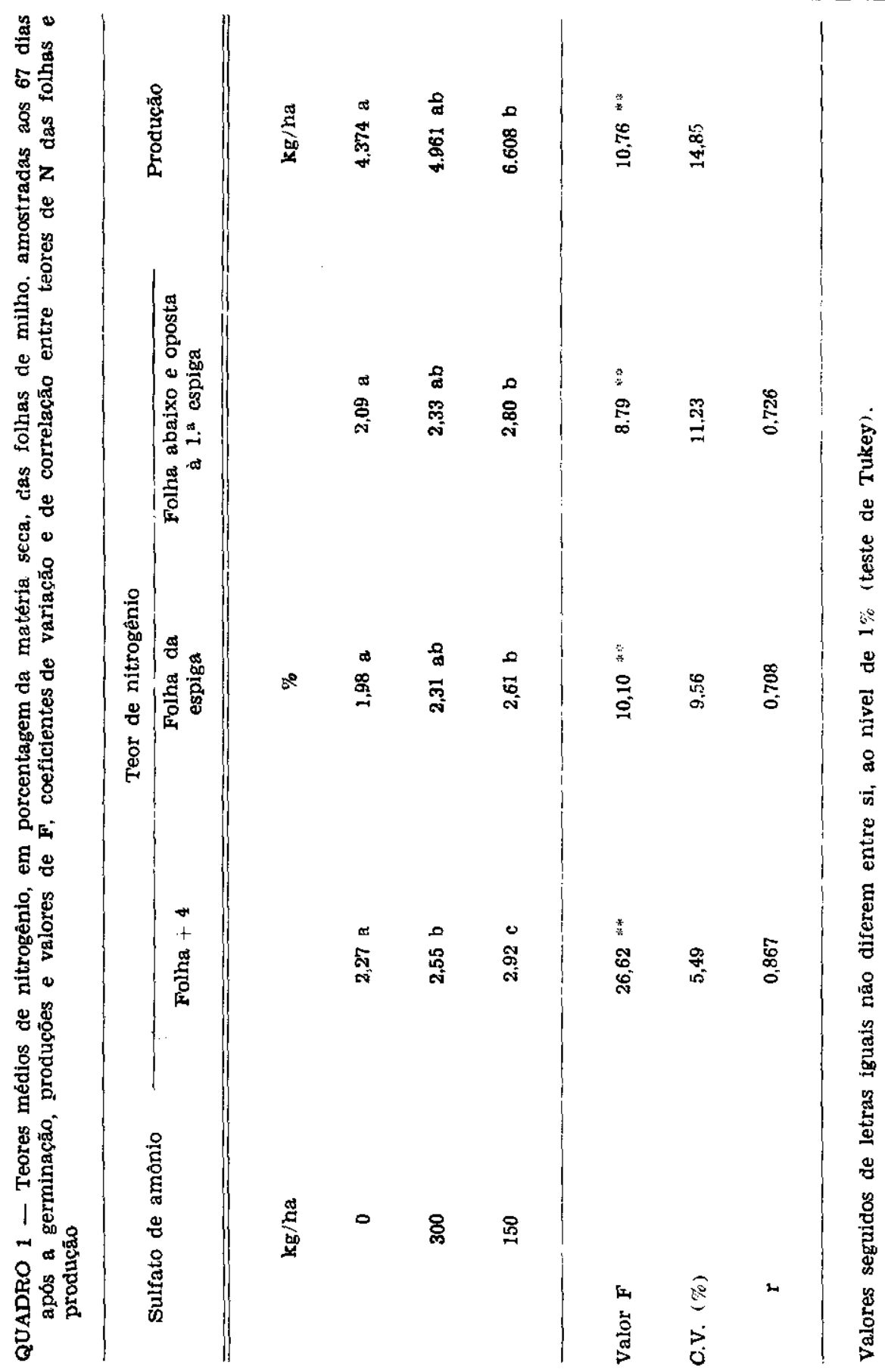




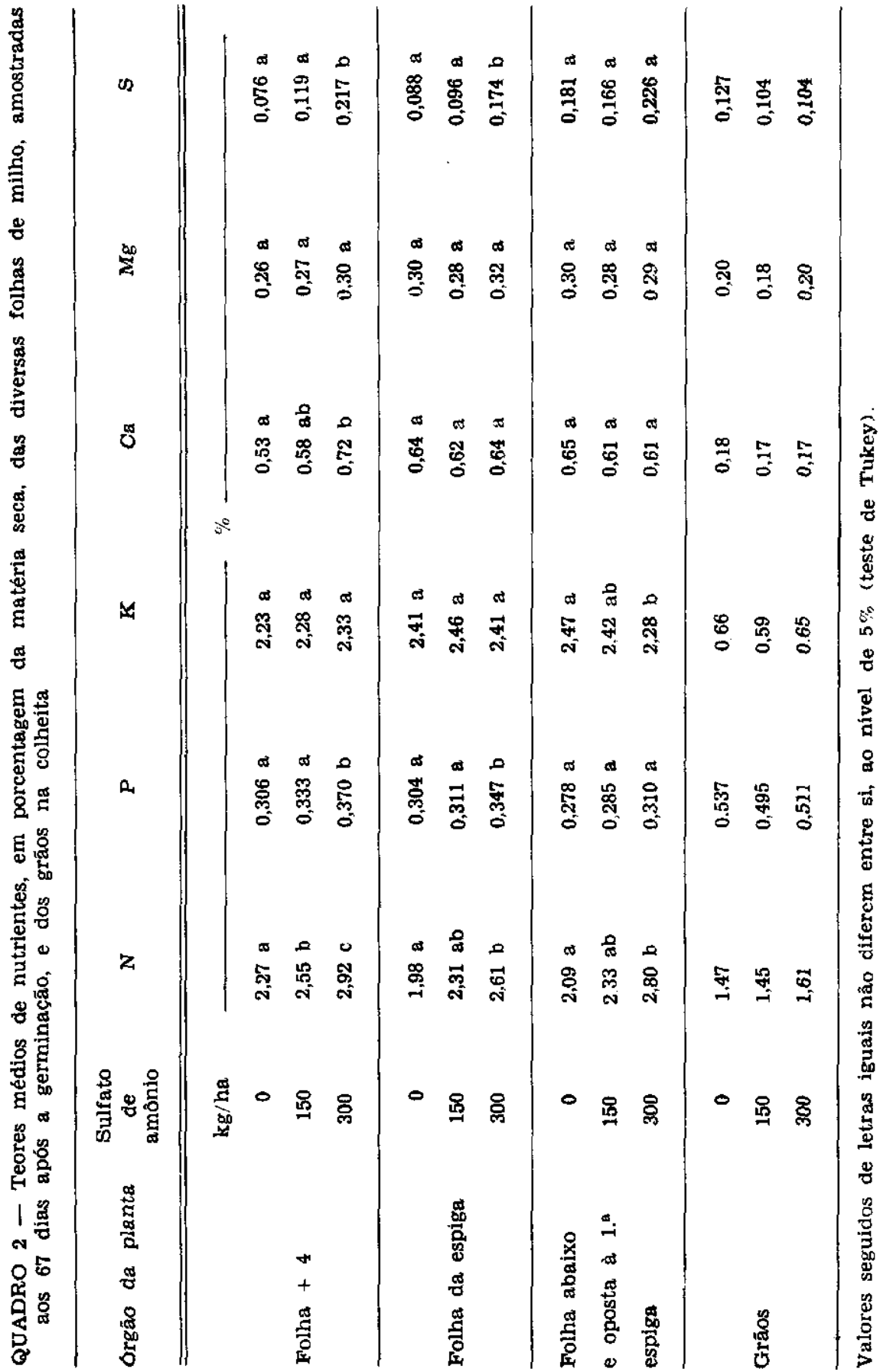




\section{CORN LEAF SAMPLING FOR NITROGEN DIAGNOSIS}

\section{SUMMARY}

Corn leaf samples were taken at different positions of the stalk in order to find out the best correlation between $\mathrm{N}$ content in the leaf and grain yield. The experiment was carried out on a Ortho-Red-Yellow soll at Mococa Experimental Station. The experiment was a randomized block design with five replications. The treatments consisted of application as side dressing of 0,30 and $60 \mathrm{~kg} N /$ ha as ammonium sulphate. At planting time the quantity of fertilizer applied was $300 \mathrm{~kg} / \mathrm{ha}$ of the formula 4-14-8. At flowering, leaf +4 , ear leaf and the leaf below and opposite to the first corn ear were sampled.

The leaves from the three sampling methods and the grain yield at harvesting time were analysed for total $\mathbf{N}, \mathbf{P}, \mathbf{K}, \mathrm{Ca}, \mathbf{M g}$ and $\mathbf{S}$. The application of $\mathbf{S}$ fertilizer showed pronounced effect on the content of $\mathrm{N}$ in the leaves +4 . There were no significant differences among correlation coefficients obtained between $\mathbf{N}$ content of the different leaves and grain yield. Further, the $\mathrm{N}$ fertilizer had a positive effect on the $P, C a$ and $S$ content of the leaves +4 , on the $P$ and $S$ content of ear leaves and on the $\mathrm{K}$ content of the leaves below and opposite to the first corn ear. Nitrogen application did not have a pronounced effect on the content of nutrientes in the grain yield. The leaf +4 showed the least coefficient of variation for nitrogen nutrition diagnosis.

\section{REFERENCIAS BIBLIOGRAFICAS}

1. ANDRADE, A. G. Acumulação diferencial de nutrientes por cinco cultivares de milho (Zea mays L.). Piracicaba, Escola Superior de Agricultura Luiz de Queiroz, 1975. 91p. (Dissertação de Mestrado)

2. ARNON, I. Determining fertilizer requirements. In: MINERAL nutrition of maize. Bern, International Potash Institute, 1975. p.245-279.

3. Bataglia, O. C.; TEIXeira, J. P. F.; FURLANI, P. R.; FURLANI, A. M. C.; GALLO, J. R. Métodos de análise química de plantas. Campinas, Instituto Agronômico, 1978. 31p. (Circular, 87)

4. GALLO, J. R. \& COELHO, F. A. S. Diagnose da nutrição nitrogenada do milho, pela análise química das folhas. Bragantia, Campinas, 22:537-548, 1963.

5. HANWAY, J. J. Plant analysis. Guide for corn needs. Better Crops with Plant Food, 46:50-55, 1962.

6. HIROCE, R.; MIRANDA, L. T.; SOARES, E. Contaminação de parcelas de ensaio de milho por nutrientes aplicados em parcelas adjacentes. Revista Brasileira de Ciência do Solo, Campinas, 3:190-193, 1979.

7. LOUE, A. Contribuiçấo para estudo da nutriçâo catiônica do milho, principalmente a do potássio. III. A nutrição catiónica do milho e a diagnose foliar. Fertilité, 20:33-50, 1963.

8. NIELSEN, K. F.; CARSON, R. B.; HOFFMAN, I. A study of the ion interactions in the uptake of nitrogen, phosphorus, potassium, calcium, chlorine and sulfur by corn. Soil science, 95:315-321, 1963.

9. PIEDRABUENA, A. E. \& BARACHO, I. R. Teste de significância entre coeficientes de correlaçāo. Ciência e Cultura, São Paulo, 28(2):191-192, 1976.

10. VOSS, R. E. HANWAY, J. J.; DUMENIL, L. C. Influence of soil management and climatic factors on the yield response by corn (Zea mays $L_{\text {c. }}$ ) to $N, P$, and K fertilizers. Agronomy Journal, 62:736-740, 1970. 